\title{
Glycal Scavenging in the Synthesis of Disaccharides Using
}

\author{
Mannosyl Iodide Donors ${ }^{\mathrm{i}}$ \\ Son N. Lam ${ }^{\dagger}$ and Jacquelyn Gervay-Hague* \\ University of California, Davis, Department of Chemistry, One Shields Ave., \\ Davis, CA 95616 \\ gervay@chem.ucdavis.edu
}

\section{Supporting Information:}

\section{Contents:}

General procedures

Experimental for 5, 6, 15, 20, and 22 .

Spectra of phase-trafficking experiments

${ }^{13} \mathrm{C}$ and ${ }^{1} \mathrm{H}$ Spectra for $\mathbf{6}, \mathbf{1 5}, \mathbf{2 0}$, and 22.

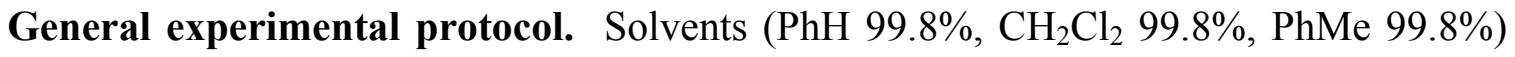
were purchased in anhyd DriSolv ${ }^{\mathrm{TM}}$ bottles, used without further purification, and stored under argon. Hünig's base (99.5\%) was purchased in Sure/Seal ${ }^{\mathrm{TM}}$ bottles, used without purification, and stored under argon. TMSI was used without purification unless the color had changed to a dark brown shade, in which case it was distilled under an argon atmosphere from quinoline prior to use. TMSI was stored at $-15^{\circ} \mathrm{C}$ under a desiccated atmosphere. Dowex 50WX8 H+ (200 mesh) resin was washed copiously with $\mathrm{MeOH}$,

\footnotetext{
${ }^{\dagger}$ Current address: National Institutes of Health, 9000 Rockville Pike, Bldg 8, Rm 1A02, Bethesda, MD 20892.

* Corresponding author. Tel.: +1-530-754-9577; fax: +1-530-752-8995; e-mail:

gervay@chem.ucdavis.edu
} 
and used without further purification. Glass-backed TLC plates (Silica Gel 60 with a 254 $\mathrm{nm}$ fluorescent indicator) were cut into $2 \mathrm{~cm} \times 5 \mathrm{~cm}$ portions, used without further manipulation, and stored over desiccant. Developed TLC plates were visualized under a short-wave UV lamp, stained with an $\mathrm{I}_{2}-\mathrm{SiO}_{2}$ mixture, and/or treated with a ceriummolybdate solution and charred. Column chromatography was conducted using flash silica gel $(32-63 \mu \mathrm{m})$. NMR experiments (1D and 2D) were conducted on DRX500 MHz and/or DRX600 MHz spectrometers using $\mathrm{C}_{6} \mathrm{D}_{6}$ and/or $\mathrm{CDCl}_{3}$ at $298 \mathrm{~K}$. 2D COSY and HSQC experiments were used to make ${ }^{1} \mathrm{H}$ and ${ }^{13} \mathrm{C}$ assignments. To distinguish between the different subunits of the oligosaccharides, ${ }^{1} \mathrm{H}$ NMR and ${ }^{13} \mathrm{C}$ NMR assignments were made with the designations "I and II with sugar "I" as the subunit at the reducing end. Optical data were taken at $25^{\circ} \mathrm{C}$ on a Digital Polarimeter.

Synthesis of 6- $O$-acetyl-2,3,4-tri- $O$-benzyl- $\alpha$-D-mannopyranosyl iodide (5): Di-

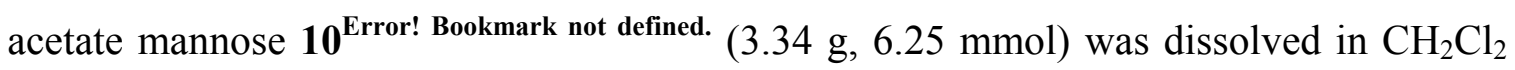
(70 mL) under argon. The solution was cooled to $0{ }^{\circ} \mathrm{C}$ and stirred for $20 \mathrm{~min}$. To the sugar solution was slowly syringed TMSI $(1.02 \mathrm{~mL}, 7.51 \mathrm{mmol})$. After $2 \mathrm{~h}$, anhydrous $\mathrm{PhMe}$ was added to the reaction and the solution was concentrated in vacuo, $\mathrm{R}_{\mathrm{f}}=0.41$ in $30 \%$ EtOAc/hexanes. The resulting oil was continuously azeotroped from dry $\mathrm{PhMe}$ until a clear distillate persisted $(5 \times 20 \mathrm{~mL})$. The glycosyl iodide 5 was redissolved in anhydrous $\mathrm{PhH}(10 \mathrm{~mL})$, stored under an argon atmosphere, and used without further manipulations.

Synthesis of Phenyl 2,3,4-tri-O-benzyl- $\alpha$-D-mannopyranoside (6): $\alpha$-Phenyl mannoside $11^{\mathrm{ii}}(1.74 \mathrm{~g}, 3.06 \mathrm{mmol})$ was dissolved in dry $\mathrm{MeOH}(20 \mathrm{~mL})$ and placed under argon. To the stirring solution was added $500 \mu \mathrm{L}$ of $30 \% \mathrm{NaOMe} / \mathrm{MeOH}$ and the 
mixture was allowed to react overnight at rt. TLC (30\% EtOAc/Hexanes) revealed the complete consumption of 11, and Dowex 50WX8 $\mathrm{H}^{+}$was added to neutralize the base. Chromatography over a short plug of silica gel afforded the $1.55 \mathrm{~g}$ of $\mathbf{6}, 96 \%$ yield. $[\alpha]_{\mathrm{D}}{ }^{25}:+61^{\circ}\left(c 0.9, \mathrm{CHCl}_{3}\right) .{ }^{1} \mathrm{H}-\mathrm{NMR}\left(\mathrm{C}_{6} \mathrm{D}_{6}, 500 \mathrm{MHz}\right) \delta 7.44(\mathrm{t}, 4 \mathrm{H}, J 7.5 \mathrm{~Hz}, \mathrm{PhH})$, 7.38 (d, 2H, J 7.5 Hz, PhH), 7.30 - 7.17 (m, 13H, PhH), 6.98 (t, 1H, J 7.5 Hz), 5.70 (d, 1H, J 1.0 Hz, H-1), 5.07 (d, 1H, J 11.0 Hz, $\mathrm{PhCH}_{2}$ ), 4.80 (d, 1H, J 11.0 Hz, $\mathrm{PhCH}_{2}$ ), 4.75 (d, $\left.1 \mathrm{H}, J 12.0 \mathrm{~Hz}, \mathrm{PhCH}_{2}\right), 4.65$ (d, 1H, J $11.5 \mathrm{~Hz}, \mathrm{PhCH}_{2}$ ), 4.63 (d, $1 \mathrm{H}, J 12.0 \mathrm{~Hz}$, $\mathrm{PhCH}_{2}$ ), 4.57 (d, 1H, J 11.5 Hz, $\mathrm{PhCH}_{2}$ ), 4.49 (t, 1H, J 9.5 Hz, H-4), 4.31 (dd, 1H, J 3.0 Hz, 9.5 Hz, H-3), 4.02 (apparent t, 1H, J 2.5 Hz, H-2), 3.95 (apparent dt, 1H, $J 2.5 \mathrm{~Hz}$, $9.5 \mathrm{~Hz}, \mathrm{H}-5), 3.86$ (m, 1H, H-6), 3.79 (m, 1H, H-6'), 2.28 (s, 1H, OH). HSQC ( $\mathrm{C}_{6} \mathrm{D}_{6}$,

$500 \mathrm{MHz})$ without ${ }^{1} \mathrm{H}$-decoupling: $J_{\mathrm{H} 1, \mathrm{C} 1}=169.1 \mathrm{~Hz} .{ }^{13} \mathrm{C}-\mathrm{NMR}\left(\mathrm{C}_{6} \mathrm{D}_{6}, 125 \mathrm{MHz}\right) \delta$ 156.6 (Ph-C), 139.11 (Ph-C), 138.9 (Ph-C), 138.6 (Ph-C), 129.7 (Ph-CH), 128.4 (PhCH), 128.4 (Ph-CH), 128.2 (Ph-CH), 128.1 (Ph-CH), 127.9 (Ph-CH), 127.7 (Ph-CH), 127.6 (Ph-CH), 127.5 (Ph-CH), 127.4 (Ph-CH), 122.5 (Ph-CH), 116.7 (Ph-CH), 97.0 (C1), 80.2 (C-3), 75.6 (C-2), 74.9 (OBn), 74.6 (C-4), 73.8 (C-5), 73.2 (OBn), 72.3 (OBn), 61.8 (C-6). MALDI-HRMS $m / z[\mathrm{M}+\mathrm{Na}]^{+}$calcd for $\mathrm{C}_{33} \mathrm{H}_{34} \mathrm{NaO}_{6}:$ 549.2253, found: 549.2238 .

\section{Synthesis of Phenyl 2,3,4-tri- $O$-benzyl-D-mannopyranosyl- $\alpha-(1 \rightarrow 6)-2,3,4-$ tri- $O$ -} benzyl- $\alpha$-D-mannopyranoside (15): A solution of glycosyl acceptor 6 (1.14 g, 2.16 mmol), TBAI (3.18 g, $8.63 \mathrm{mmol})$, DIPEA (960 $\mu \mathrm{L}, 5.40 \mathrm{mmol})$, and $4 \AA \mathrm{MS}(3.00 \mathrm{~g})$ in $\mathrm{PhH}(10 \mathrm{~mL})$ was stirred under argon for $30 \mathrm{~min}$ at $\mathrm{rt}$. A solution of glycosyl donor 5 (4.31 mmol) in $\mathrm{PhH}(5 \mathrm{~mL})$ was cannulated into the flask containing 6. The mixture was then heated at $80{ }^{\circ} \mathrm{C}$ for $7 \mathrm{~h}$. After which time, TLC (35\% EtOAc/hexanes) revealed the 
absence of $\mathbf{6}$ and the presence of glycal $14\left(R_{f}=0.52\right)$. The reaction was diluted with EtOAc $(50 \mathrm{~mL})$ and cooled to $0{ }^{\circ} \mathrm{C}$, precipitated TBAI and $4 \AA$ MS were removed by filtration over a pad of Celite. The mother liquor was washed with sat'd aq. $\mathrm{Na}_{2} \mathrm{~S}_{2} \mathrm{O}_{3}(2 \mathrm{x}$ $20 \mathrm{~mL})$ and brine $(2 \times 10 \mathrm{~mL})$. The organic layer was dried over $\mathrm{MgSO}_{4}$ and concentrated in vacuo. ${ }^{1} \mathrm{H}-\mathrm{NMR}$ spectrum of the crude mixture revealed the presence of glycal 14 and other carbohydrate-like resonances. Attempts to purify the mixture through silica gel column chromatography were futile. The crude material was redissolved in a solution of $\mathrm{MeOH} / \mathrm{CH}_{2} \mathrm{Cl}_{2}(90: 30 \mathrm{~mL})$ and was treated with $30 \% \mathrm{NaOMe} / \mathrm{MeOH}(1 \mathrm{~mL})$ for $3 \mathrm{~h}$. TLC in $35 \%$ EtOAc/Hexanes revealed a spot with $\mathrm{R}_{\mathrm{f}}=0.30$ (disaccharide 15) and a second spot $R_{f}=0.23$ (deacetylated glycal). Silica gel column chromatography using $25 \%$ EtOAc/Hexanes as the eluent afforded $1.84 \mathrm{~g}$ of disaccharide $15,89 \%$ yield over 2 steps. $[\alpha]_{\mathrm{D}}{ }^{25}:+107^{\circ}\left(c 1.0, \mathrm{CHCl}_{3}\right) .{ }^{1} \mathrm{H}-\mathrm{NMR}\left(\mathrm{C}_{6} \mathrm{D}_{6}, 500 \mathrm{MHz}\right) \delta 7.46-7.27(\mathrm{~m}$, 11H, PhH), $7.24-7.28$ (m, 23H, PhH), 6.95 (t, 1H, J 7.5 Hz, PhH), 5.70 (s, 1H, H-1'), 5.16 (s, 1H, H-1' '), 5.14 (d, 1H, J 12.0 Hz, $\mathrm{PhCH}_{2}$ ), 5.09 (d, 1H, J $11.0 \mathrm{~Hz}, \mathrm{PhCH}_{2}$ ), 4.70 (apparent t, 3H, $J 12.5 \mathrm{~Hz}, \mathrm{PhCH}_{2}, \mathrm{PhCH}_{2}, \mathrm{PhCH}_{2}$ ), 4.63 (d, 1H, $J 12.5 \mathrm{~Hz}, \mathrm{PhCH}_{2}$ ), 4.60 - 4.53 (m, 6H, $\mathrm{PhCH}_{2}, \mathrm{PhCH}_{2}, \mathrm{PhCH}_{2}, \mathrm{PhCH}_{2}, \mathrm{PhCH}_{2}, \mathrm{PhCH}_{2}$ ), 4.38 (t, 1H, J 9.5 Hz, H4' '), 4.36 - 4.31 (m, 2H, H-4', H-3'), 4.18 (dd, 1H, J 2.5, 9.5 Hz, H-3') ), 4.14 (br, 1H, H5'), 4.01 (br, 3H, H-6', H-5', H-2'), 3.93 (broad d, 3H, H-6', H-6', H-2'”), 3.73 (br d, $1 \mathrm{H}, J 11.0 \mathrm{~Hz}, \mathrm{H}-6$ '). $\mathrm{HSQC}\left(\mathrm{C}_{6} \mathrm{D}_{6}, 500 \mathrm{MHz}\right)$ without ${ }^{1} \mathrm{H}$-decoupling: $J_{\mathrm{H} 1, \mathrm{C} 1}=172.0$ Hz. ${ }^{13} \mathrm{C}-\mathrm{NMR}\left(\mathrm{C}_{6} \mathrm{D}_{6}, 125 \mathrm{MHz}\right) \delta 156.9$ (Ph-C), 139.5 (Ph-C), 139.3 (Ph-C), 139.2 (PhC), 139.2 (Ph-C), 139.0 (Ph-C), 138.7 (Ph-C), 130.0 (Ph-CH), 129.9 (Ph-CH), 129.6 (PhCH), 129.2 (Ph-CH), 128.8 (Ph-CH), 128.8 (Ph-CH), 128.6 (Ph-CH), 128.6 (Ph-CH), 128.5 (Ph-CH), 128.5 (Ph-CH), 128.4 (Ph-CH), 128.3 (Ph-CH), $128.2(\mathrm{Ph}-\mathrm{CH}), 128.1$ 
(Ph-CH), 127.9 (Ph-CH), 127.9 (Ph-CH), 127.8 (Ph-CH), 127.7 (Ph-CH), 127.7 (Ph-CH), 127.5 (Ph-CH), 127.4 (Ph-CH), 122.6 (Ph-CH), 117.0 (Ph-CH), 116.8 (Ph-CH), 98.6 (C1’'), 96.8 (C-1'), 80.7 (C-4'”), 80.2 (C-3')), 76.0 (C-2')), 75.7 (C-2'), 75.3 (OBn), 75.2 (OBn), 75.0 (C-4'), 74.9 (C-3'), 73.3 (OBn), 73.2 (OBn), 73.2 (OBn), 72.8 (C-5'), 72.4 (C-5'), 71.8 (OBn), 66.5 (C-6'), 62.4 (C-6’). MALDI-HRMS m/z [M+Na] $]^{+}$calcd for $\mathrm{C}_{60} \mathrm{H}_{62} \mathrm{NaO}_{11}: 981.4190$, found: 981.4152 .

Synthesis of Phenyl 2- $O$-acetyl-3,4,6-tri- $O$-benzyl- $\alpha$-D-mannopyranoside (20): A flask containing tri- $O$-benzyl orthoester $\mathbf{1 9}^{\mathrm{iii}}(2.00 \mathrm{~g}, 4.03 \mathrm{mmol})$ and $\mathrm{PhOH}(3.79 \mathrm{~g}, 40.3$ mmol) was charged with anhydrous $\mathrm{CH}_{2} \mathrm{Cl}_{2}(20 \mathrm{~mL})$. Following the addition of $\pm \mathrm{CSA}$ (433 mg, $1.86 \mathrm{mmol})$, the mixture was refluxed overnight (14 h). TLC analyses (30\% EtOAc/hexanes) showed the presence of a major spot, $R_{f}=0.45$. The reaction was diluted with $\mathrm{CH}_{2} \mathrm{Cl}_{2}(100 \mathrm{~mL})$ and washed with sat'd aq. $\mathrm{K}_{2} \mathrm{CO}_{3}(5 \times 50 \mathrm{~mL})$. The organic layer was dried over $\mathrm{MgSO}_{4}$ and concentrated in vacuo. Following silica gel column chromatography using 10\% EtOAc/Hexanes, $1.31 \mathrm{~g}$ of phenyl mannoside $\mathbf{2 0}$ was obtained, $57 \%$ yield. $[\alpha]_{\mathrm{D}}^{25}:+43^{\circ}\left(c 1.0, \mathrm{CHCl}_{3}\right) .{ }^{1} \mathrm{H}-\mathrm{NMR}\left(\mathrm{C}_{6} \mathrm{D}_{6}, 500 \mathrm{MHz}\right) \delta 7.45(\mathrm{~d}$, 2H, J 7.5 Hz, PhH), 7.35 (t, 4H, J 7.5 Hz, PhH), $7.27-7.18$ (m, 13H, PhH), 6.97 (t, 1H, $J$ $7.5 \mathrm{~Hz}, \mathrm{PhH}), 5.91$ (t, 1H, J 1.5 Hz, H-2), 5.68 (d, 1H, J 1.5 Hz, H-1), 5.12 (d, 1H, J 11.0 $\left.\mathrm{Hz}, \mathrm{PhCH}_{2}\right), 4.77$ (d, 1H, J 11.0 Hz, $\left.\mathrm{PhCH}_{2}\right), 4.73$ (d, 1H, J 11.0 Hz, $\left.\mathrm{PhCH}_{2}\right), 4.54$ (d, 1H, $J 11.0 \mathrm{~Hz}, \mathrm{PhCH}_{2}$ ), 4.50 (d, 1H, $J 11.0 \mathrm{~Hz}, \mathrm{PhCH}_{2}$ ), 4.43 - 4.36 (m, 3H, H-3, H-4, PhCH $)_{2}$, 4.17 (dd, 1H, J $3.8 \mathrm{~Hz}, 10.0 \mathrm{~Hz}, \mathrm{H}-5$ ), 3.84 (dd, 1H, J $3.8 \mathrm{~Hz}, 10.0 \mathrm{~Hz}, \mathrm{H}-6$ ), $3.63(\mathrm{~d}, 1 \mathrm{H}, J 10.0 \mathrm{~Hz}, \mathrm{H}-6), 1.84(\mathrm{~s}, 3 \mathrm{H}, \mathrm{OAc})$. HSQC $\left(\mathrm{C}_{6} \mathrm{D}_{6}, 500 \mathrm{MHz}\right)$ without ${ }^{1} \mathrm{H}-$ decoupling: $J_{\mathrm{H} 1, \mathrm{C} 1}=172.0 \mathrm{~Hz} .{ }^{13} \mathrm{C}-\mathrm{NMR}\left(\mathrm{C}_{6} \mathrm{D}_{6}, 125 \mathrm{MHz}\right) \delta 169.8(\mathrm{C}=\mathrm{O}), 156.7(\mathrm{Ph}-$ C), 139.4 (Ph-C), 139.1 (Ph-C), 138.6 (Ph-C), 129.8 (Ph-CH), 128.6 (Ph-CH), 128.5 (Ph- 
CH), 128.4 (Ph-CH), 128.38 (Ph-CH), 128.2 (Ph-CH), 127.8 (Ph-CH), 127.6 (Ph-CH), 127.6 (Ph-CH), 122.8 (Ph-CH), 117.1 (Ph-CH), 96.9 (C-1), 78.7 (C-3), 75.2 (OBn), 74.7 (C-4), 73.4 (OBn), 72.9 (C-5), 72.1 (OBn), 69.2 (C-6), 68.9 (C-2), 20.5 (OAc). MALDIHRMS $m / z[\mathrm{M}+\mathrm{Na}]^{+}$calcd for $\mathrm{C}_{35} \mathrm{H}_{36} \mathrm{NaO}_{7}:$ 591.2359, found: 591.2364.

\section{Synthesis of phenyl 6- $O$-acetyl-2,3,4-tri- $O$-benzyl-D-mannopyranosyl- $\alpha$-(1-2)-3,4,6-}

tri-O-benzyl- $\alpha$-D-mannopyranoside (22): A mixture of glycosyl acceptor $7^{\mathrm{iv}, v, \mathrm{vi}}(512$ mg, $0.97 \mathrm{mmol})$, TBAI (1.50 g, $4.06 \mathrm{mmol})$, DIPEA (423 mL, $2.43 \mathrm{mmol})$, and $4 \AA \mathrm{MS}$ in $\mathrm{PhH}(5 \mathrm{~mL})$ was stirred under argon at $\mathrm{rt}$ for $45 \mathrm{~min}$. A solution of glycosyl donor 5 (2.56 mmol) in $\mathrm{PhH}(1.0 \mathrm{~mL})$ was cannulated into the flask containing 7. The reaction was then heated to $80{ }^{\circ} \mathrm{C}$ for $7 \mathrm{~h}$. The reaction was diluted with EtOAc $(30 \mathrm{~mL})$ and cooled to $0{ }^{\circ} \mathrm{C}$, precipitated TBAI and $4 \AA$ MS were removed over a pad of Celite. The mother liquor was washed with sat'd aq. $\mathrm{Na}_{2} \mathrm{~S}_{2} \mathrm{O}_{3}(2 \times 20 \mathrm{~mL})$ and brine $(2 \times 10 \mathrm{~mL})$. The organic layer was dried over $\mathrm{MgSO}_{4}$ and concentrated in vacuo. The crude mixture passed through a small plug of silica gel and eluted with $25 \%$ EtOAc/Hexanes. The major spot was revealed to be an inseparable mixture of glycal $\mathbf{1 4}$ and disaccharide 22, $1.51 \mathrm{~g}, \mathrm{R}_{\mathrm{f}}=0.52\left(35 \%\right.$ EtOAc/hexanes). Based upon ${ }^{1} \mathrm{H}-\mathrm{NMR}$ integrations crude material and total weight, conversion of $\mathbf{1 5}$ to 22 proceeded in $86 \%$. [ $\alpha]_{\mathrm{D}}^{25}:+51^{\circ}(c 1.0$, $\left.\mathrm{CHCl}_{3}\right) .{ }^{1} \mathrm{H}-\mathrm{NMR}\left(\mathrm{C}_{6} \mathrm{D}_{6}, 500 \mathrm{MHz}\right) \delta 7.44-7.34(\mathrm{~m}, 15 \mathrm{H}, \mathrm{PhH}), 7.28-7.11(\mathrm{~m}, 9 \mathrm{H}$, PhH), 6.94 (t, 1H, J 7.5 Hz, PhH), 6.10 (s, 1H, H-1'), 5.43 (s, 1H, H-1'), 5.12 (d, 1H, $J$ $11.0 \mathrm{~Hz}, \mathrm{PhCH}_{2}$ ), 5.01 (d, 1H, J 11.0 Hz, $\mathrm{PhCH}_{2}$ ), 4.83 (d, 1H, J 11.0 Hz, $\left.\mathrm{PhCH}_{2}\right), 4.70$ (apparent d, 1H, J 11.5 Hz, H-6'), 4.65 (apparent s, 3H, $\mathrm{PhCH}_{2}, \mathrm{PhCH}_{2}, \mathrm{PhCH}_{2}$ ), 4.58 (d, 1H, J 11.0 Hz, $\mathrm{PhCH}_{2}$ ), 4.57 (d, 1H, J 11.0 Hz, $\mathrm{PhCH}_{2}$ ), $4.51-4.41$ (m, 8H, H-6', $\mathrm{PhCH}_{2}, \mathrm{PhCH}_{2}, \mathrm{PhCH}_{2}, \mathrm{PhCH}_{2}, \mathrm{H}-4$ ', H-2', H-5' '), 4.36 (dd, 1H, J 3.0 Hz, 9.5 Hz, H-3'), 
4.26 (dd, 1H, J 2.5 Hz, 9.0 Hz, H-3'’), 4.19 - 4.13 (m, 3H, H-4'’, H-2', , H-5'), 3.90 (dd, 1H, J 4.0 Hz, 11.5 Hz, H-6'), 3.65 (d, 1H, $J=11.5$ Hz, H-6'), 1.62 (s, 3H, OAc). HSQC

$\left(\mathrm{C}_{6} \mathrm{D}_{6}, 500 \mathrm{MHz}\right)$ without ${ }^{1} \mathrm{H}$-decoupling: $J_{\mathrm{H} 1, \mathrm{C} 1}=170.5 \mathrm{~Hz} .{ }^{13} \mathrm{C}-\mathrm{NMR}\left(\mathrm{C}_{6} \mathrm{D}_{6}, 125\right.$ MHz) $\delta 170.2(\mathrm{C}=\mathrm{O}), 157.0(\mathrm{Ph}-\mathrm{C}), 139.5(\mathrm{Ph}-\mathrm{C}), 139.3$ (Ph-C), $139.2(\mathrm{Ph}-\mathrm{C}), 139.1$ (Ph-C), 139.0 (Ph-C), 138.8 (Ph-C), 130.0 (Ph-CH), 128.7 (Ph-CH), 128.6 (Ph-CH), 128.5 (Ph-CH), 128.4 (Ph-CH), 128.3 (Ph-CH), 128.1 (Ph-CH), $127.9(\mathrm{Ph}-\mathrm{CH}), 127.9$ (Ph-CH), 127.8 (Ph-CH), 127.7 (Ph-CH), 127.68 (Ph-CH), 127.6 (Ph-CH), 122.8 (PhCH), 117.1 (Ph-CH), 100.7 (C-1'’), 98.1 (C-1'), 80.7 (C-3’'), 80.1 (C-3’), 75.9 (C-2’'), 75.6 (C-2'), 75.5 (C-4’’), 75.3 (OBn), 75.3 (OBn), 75.1 (C-4'), 73.6 (OBn), 73.3 (C-5'’), 73.0 (OBn), 72.7 (C-5’), 72.2 (OBn), 71.8 (OBn), 69.4 (C-6’), 64.4 (C-6’’), 20.3 (OAc). MALDI HRMS $m / z[\mathrm{M}+\mathrm{Na}]^{+}$calcd for $\mathrm{C}_{62} \mathrm{H}_{64} \mathrm{NaO}_{12}$ : 1023.4296, found: 1023.4260 .

Phase trafficking with DMDO and PS-OH resin: Crude mixture of $\mathbf{1 4}$ and 22 (106 $\mathrm{mg}, 0.06 \mathrm{mmol}$ of 22, $0.10 \mathrm{mmol}$ of 14) was dissolved in $\mathrm{CH}_{2} \mathrm{Cl}_{2}(5 \mathrm{~mL})$. After addition of PS-OH (96 mg, $0.14 \mathrm{mmol}$ ) the mixture was placed under argon and cooled to $-50{ }^{\circ} \mathrm{C}$. Freshly prepared DMDO in acetone $(1.5 \mathrm{~mL}, \sim 1.5 \mathrm{mmol})$ was syringed into the cooled heterogeneous mixture. The reaction stirred for $3 \mathrm{~h}$, after which the resin was filtered off and the filtrate concentrated in vacuo. Based upon ${ }^{1} \mathrm{H}-\mathrm{NMR}$ integrations, $76 \%$ of the glycal 14 reacted with DMDO and $60 \%$ of the glycal had been removed from the solution.

Phase trafficking with DMDO and norbornene 2-methanol 28 and ROMP: A crude mixture of 14 and $22(142 \mathrm{mg}, 0.08 \mathrm{mmol}$ of 22, $0.13 \mathrm{mmol}$ of 14) along with 28 (36 mg, $0.29 \mathrm{mmol})$ was dissolved in $\mathrm{CH}_{2} \mathrm{Cl}_{2}(1 \mathrm{~mL})$. The mixture was placed under argon and cooled to $-30{ }^{\circ} \mathrm{C}$. Freshly prepared DMDO in acetone $(1.5 \mathrm{~mL}, \sim 1.5 \mathrm{mmol})$ was added 
and the reaction was stirred for $5 \mathrm{~h}$. TLC (35\% EtOAc/hexanes) revealed spots corresponding to $28\left(\mathrm{R}_{\mathrm{f}}=0.57\right)$ and $22\left(\mathrm{R}_{\mathrm{f}}=0.52\right)$ and a streak, norbornene methyl glycosides $\left(R_{\mathrm{f}}=0.40-0.30\right)$. The mixture was then concentrated in vacuo and analyzed according to the ${ }^{1} \mathrm{H}-\mathrm{NMR}$ spectrum, which revealed the absence of glycal 14 (6.30 ppm) and aldehyde 25 (9.43 ppm).

The crude reaction mixture from the solution-phase phase trafficking was redissolved in freshly degassed $\mathrm{CH}_{2} \mathrm{Cl}_{2}$. A solution of Grubbs generation I catalyst in $\mathrm{CH}_{2} \mathrm{Cl}_{2}(0.1 \mathrm{M}, 60 \mu \mathrm{L})$ was added to the mixture. The reaction was refluxed for $1 \mathrm{~h}$ and ethyl vinyl ether $(250 \mu \mathrm{L})$ was added. By visual inspection, a gelatinous polymer had formed. Heptane $(10 \mathrm{~mL})$ was added to a dried sample of the polymer and disaccharide (76 mg, $0.04 \mathrm{mmol} \mathrm{22,} 0.07 \mathrm{mmol} \mathrm{14).} \mathrm{The} \mathrm{heterogeneous} \mathrm{mixture} \mathrm{was} \mathrm{warmed} \mathrm{to} \mathrm{near}$ boiling while swirling. The solvent was decanted into a test tube. A second portion of fresh heptane $(10 \mathrm{~mL})$ was added. The mixture was warmed with agitation, and the mother liquor was decanted as before, crop 2. This heterogeneous extraction was repeated 5 additional times each with $10 \mathrm{~mL}$ volumes of heptane. TLC analyses revealed a large presence of disaccharide 22 in fractions 2, 3 and 4. The fractions were combined, concentrated in vacuo, subjected to flash silica gel column chromatography $(20 \%$ EtOAc/Hexanes) to afford $32 \mathrm{mg}$ of 22. 


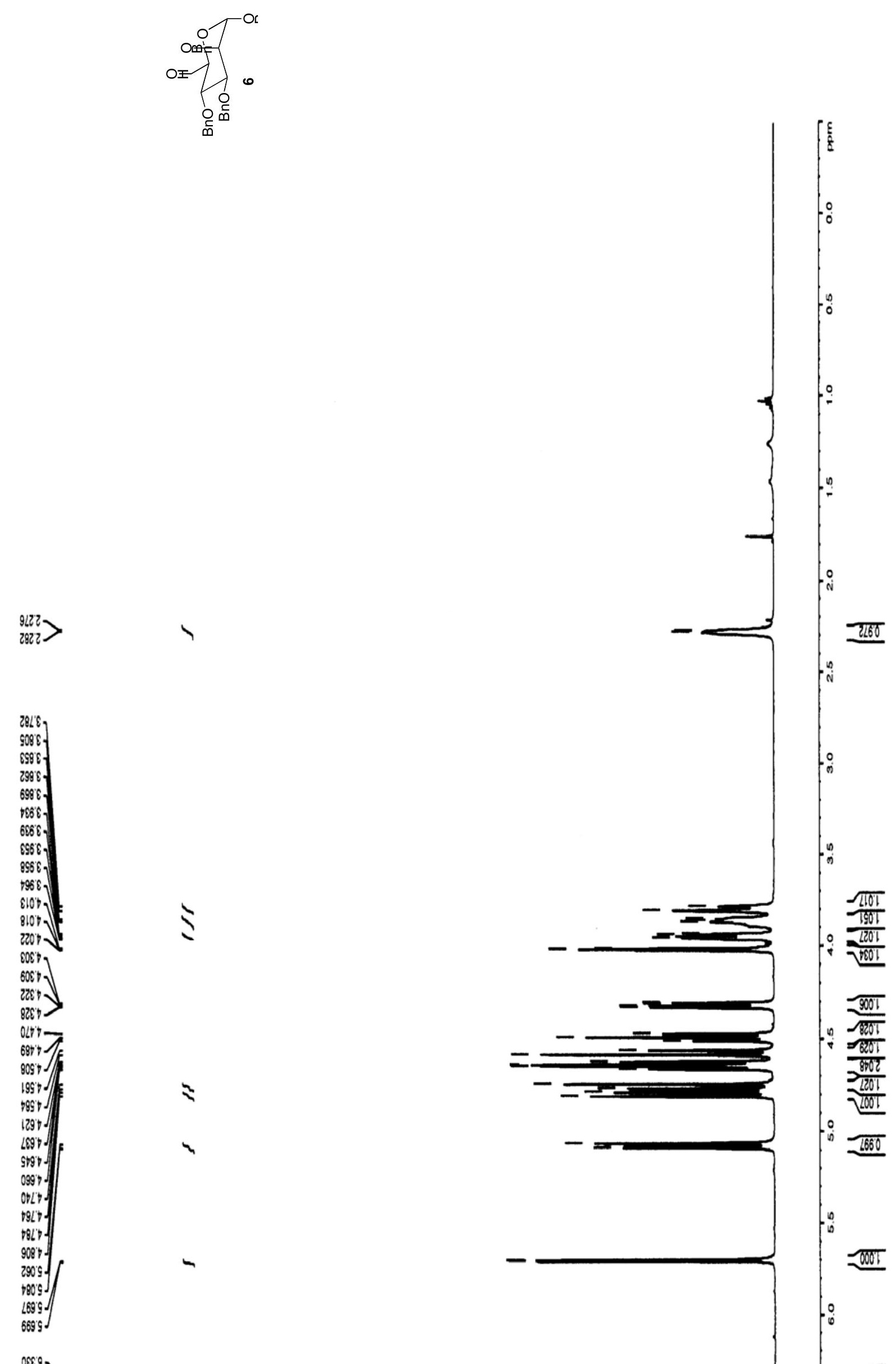



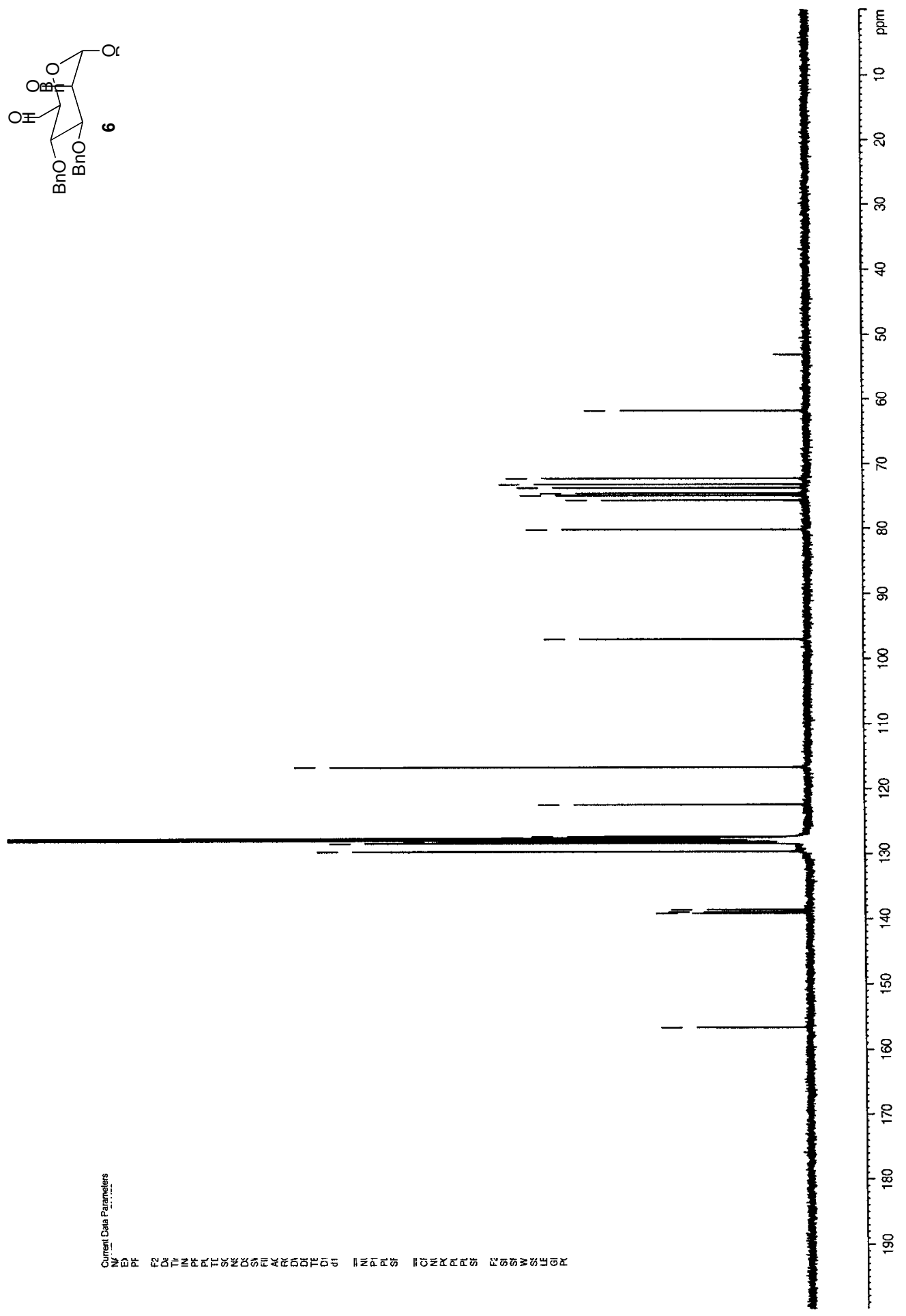


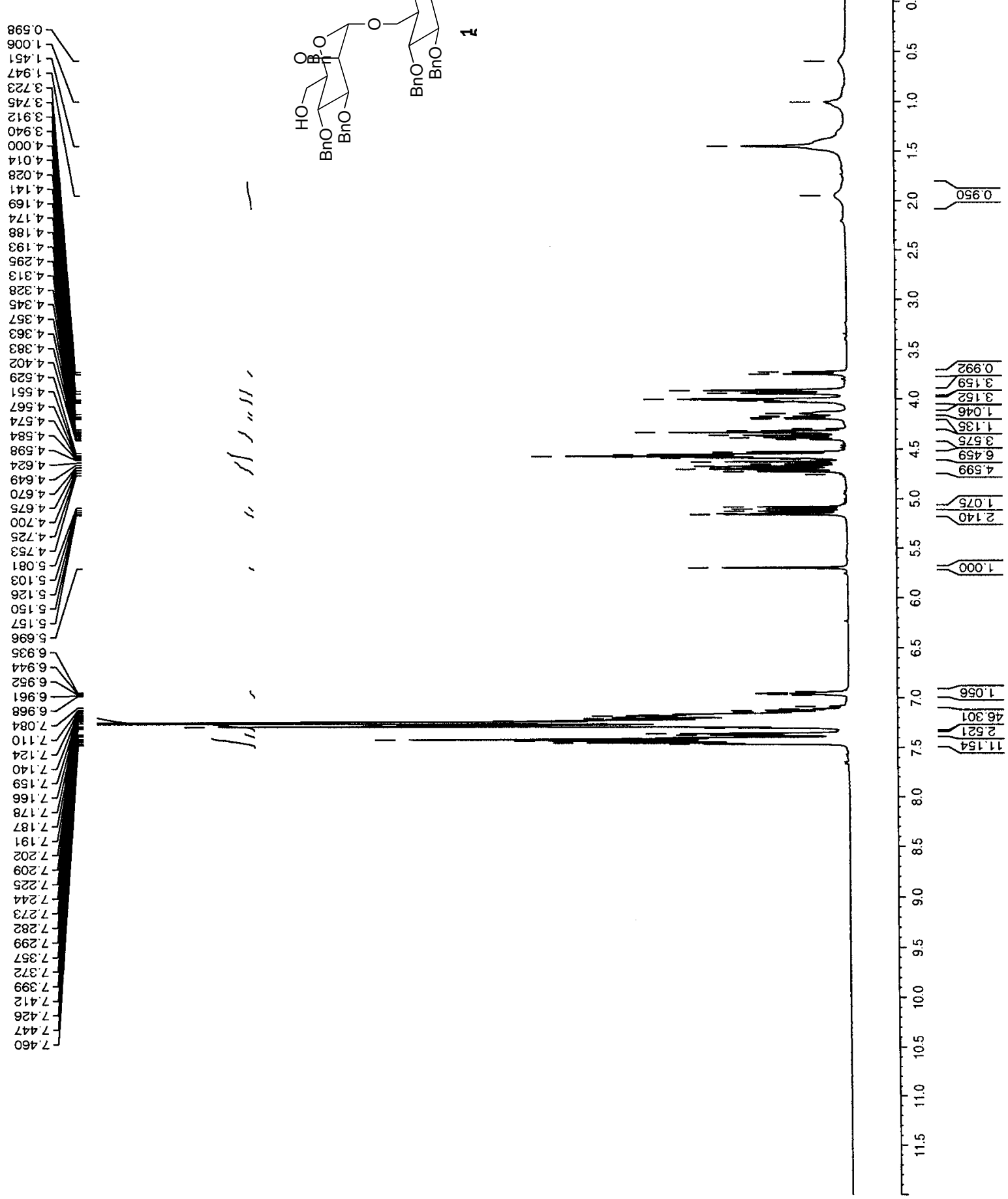



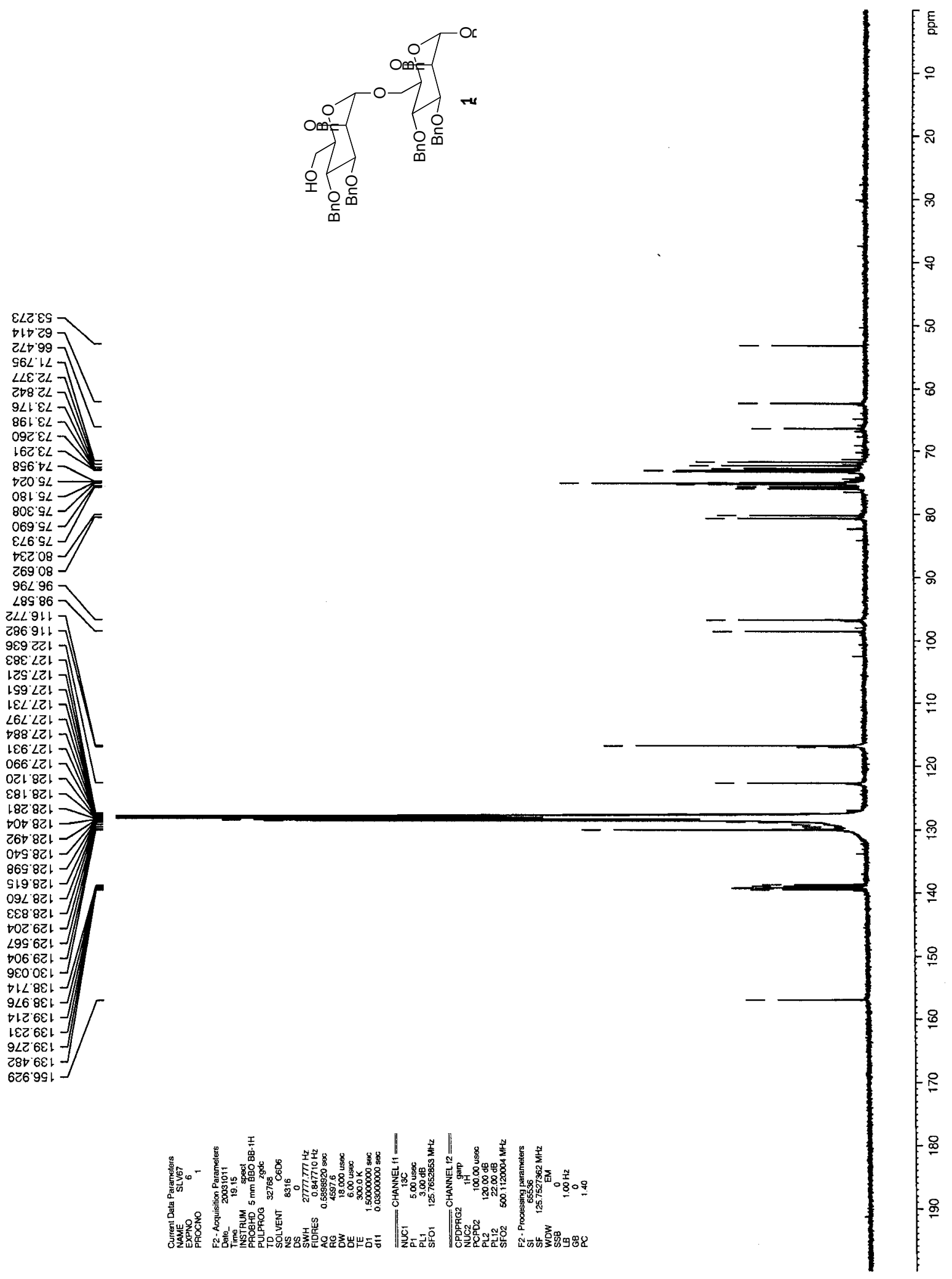


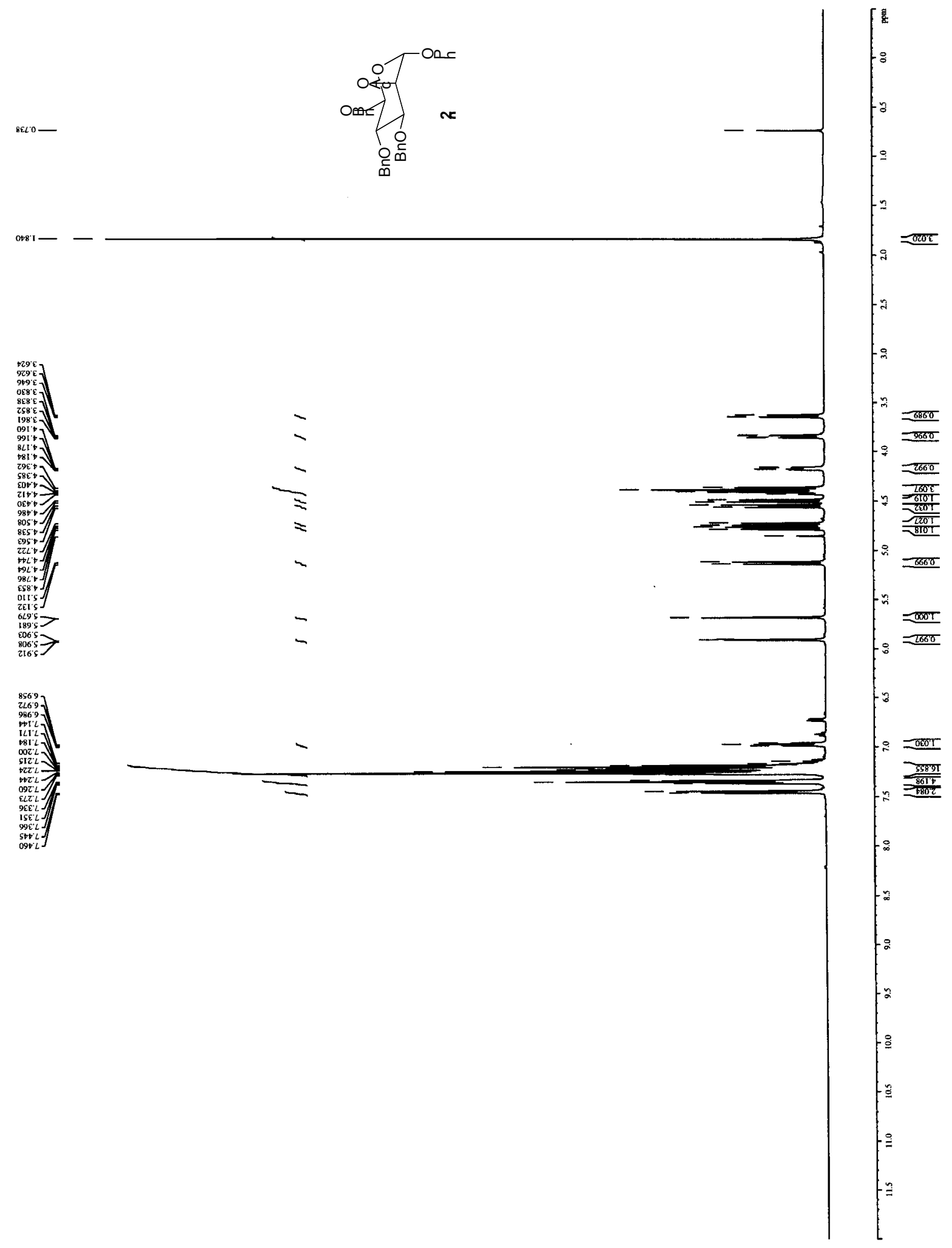


09002

986.89

$66+69$

DCl' $2 L$

86822

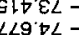

SLC'SL

61696

ozt<Ll一

6182217

$059<21$

$66 \angle \angle 21$

$266 \angle 21$

$9818 \mathrm{~B} 1$

$\varepsilon 8 z$ '8z

$08 \varepsilon .821=$

00t' $82 \mathrm{~L}-$

19t'8zt

$699.8 \mathrm{Zl}$

$6+8.621$

$6 \varepsilon 9.8 \varepsilon 1$

$28 \mathrm{~S} 6 \mathrm{6El}$

$\angle 9^{\circ} 99^{\prime}$

$69 \angle 691$
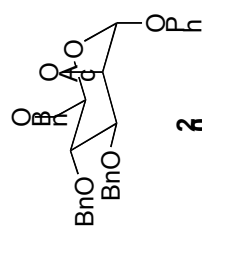

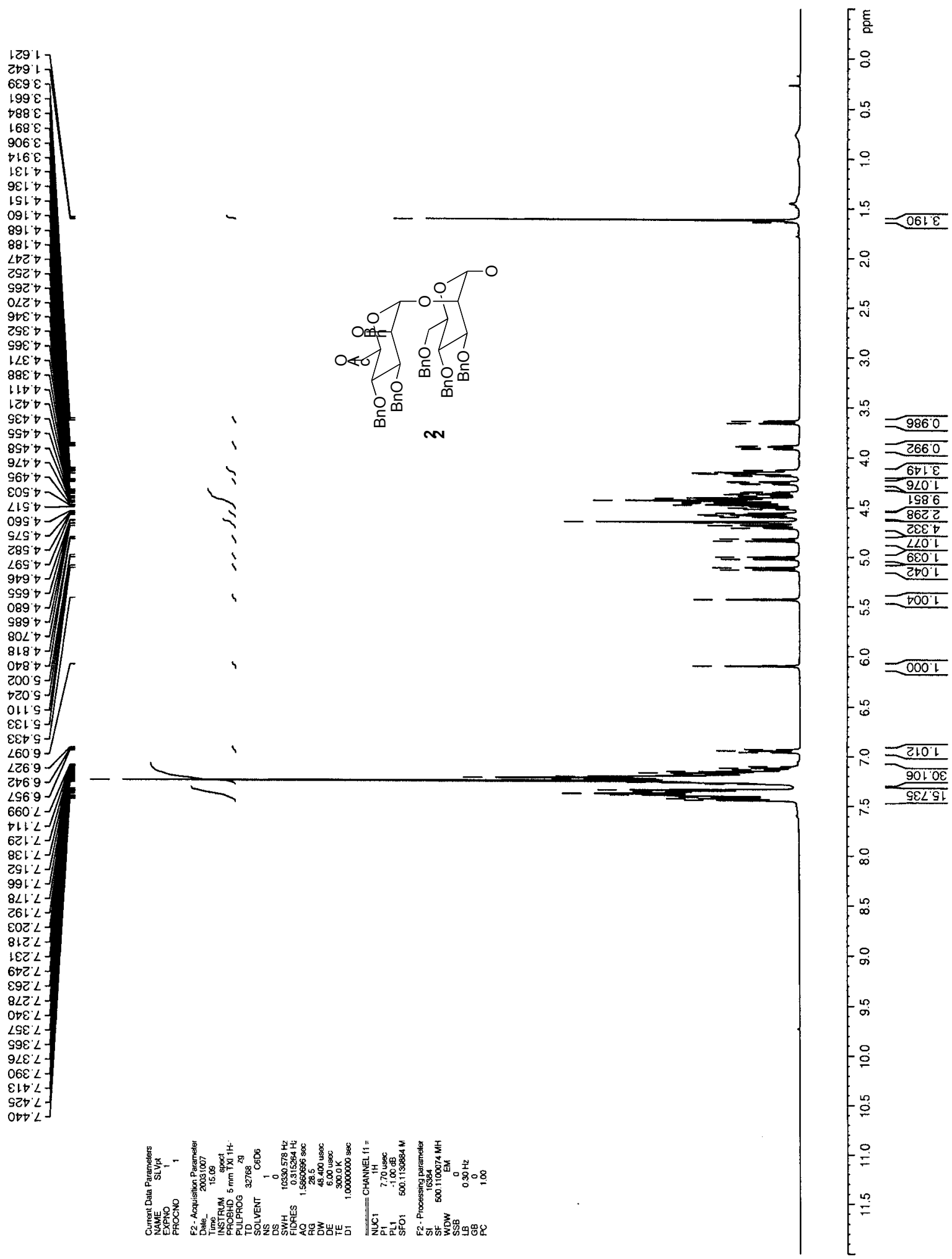
$8 \nabla 202$
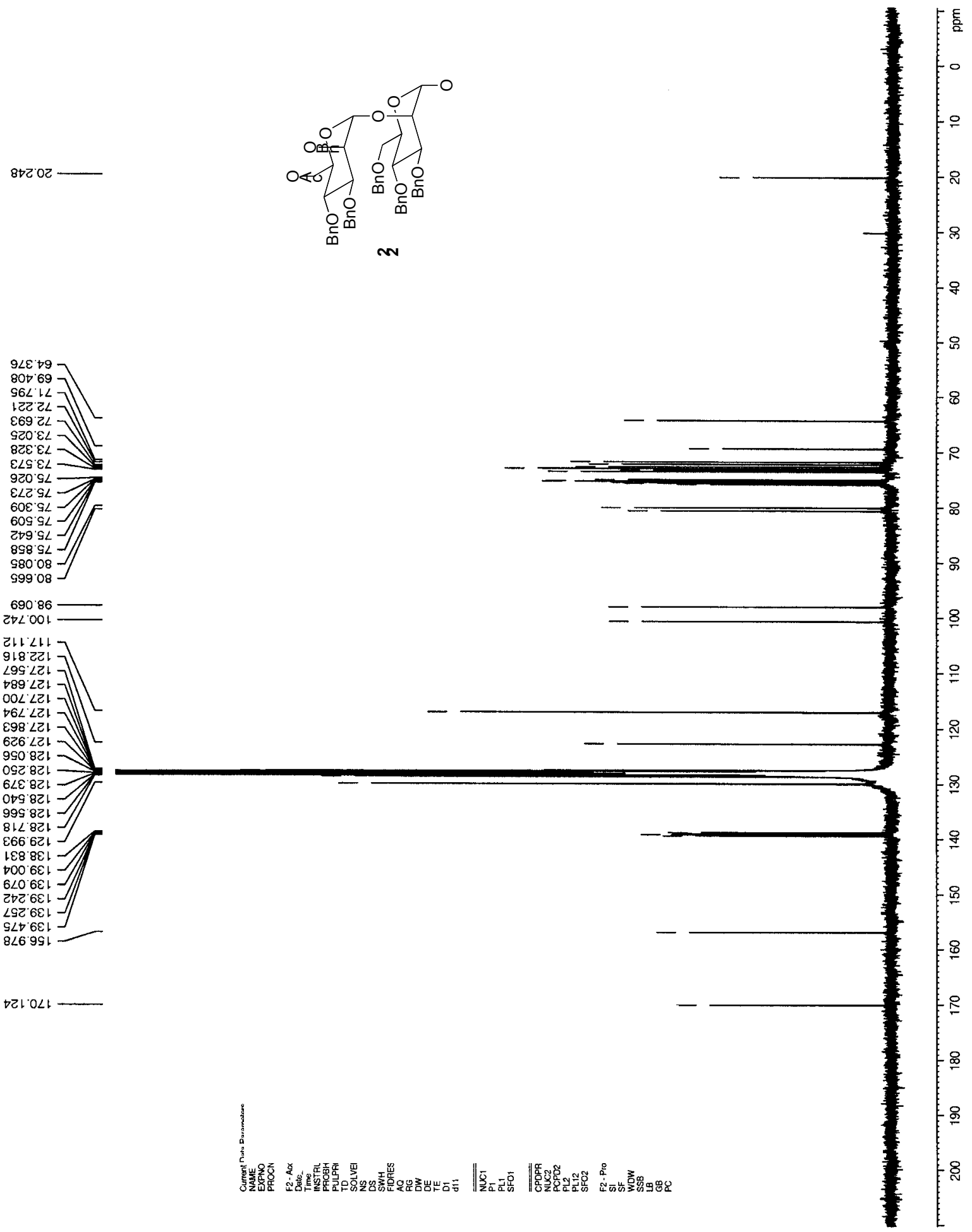

$\Delta Z 1 \cdot 0<1$ 


\section{References:}

\footnotetext{
${ }^{\mathrm{i}}$ Taken in part from the dissertation of Son Lam, University of California, Davis, 2003.

ii Yamanoi, T.; Yamazaki, I. Tetrahedron Lett. 2001, 42(24), 4009 - 4011.

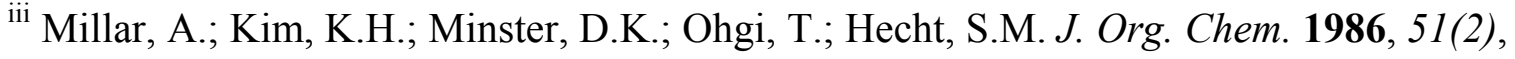
$189-196$.

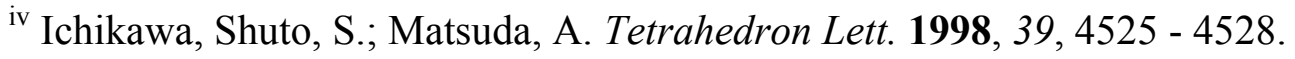

${ }^{v}$ Franks, N.E.; Montgomery, R. Carbohydr. Res. 1968, 6, 286 - 298.

${ }^{\text {vi }}$ Chernyak, A.; Demidov, I.; Kochetkov, N.K. Bioorg. Khim. 1989, 15, 1673 - 1685.
} 